\title{
Naledi: An example of how natural phenomena can inspire metaphysical assumptions
}

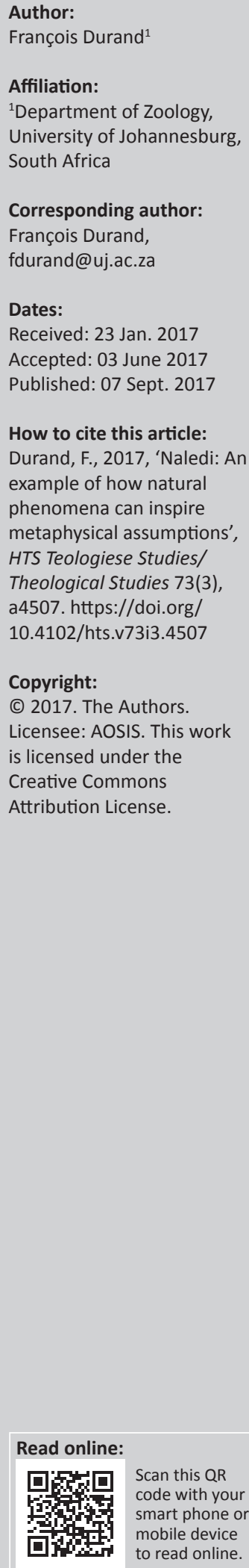

A new fossil site was discovered in the Rising Star Cave in 2013 in the Cradle of Humankind in South Africa. This site which has yielded 1550 hominin bones so far is considered to be one of the richest palaeoanthropological sites in the world. The deposition of the fossils in a remote part of the cave system, approximately $100 \mathrm{~m}$ from the entrance, has resulted in a great deal of speculation. The relative inaccessibility of the site and the number of fossil bones it contained and the fact that virtually all these bones were those of a single species of hominid led to the conclusion that the bones were not deposited because of natural sedimentary processes, but that these phenomena were evidence of purposeful disposal or even burial of the dead by hominins. If this assumption is true, it would be the earliest evidence of a metaphysical awareness in humankind. The tenuous evidence on which this hypothesis rests will be discussed and a more plausible alternative explanation where water and gravity were responsible for the deposition of the remains is forwarded.

\section{Introduction}

The dolomitic region between Krugersdorp and Hartbeespoort Dam is renowned for its palaeoanthropological treasures. The area boasts over 50 known fossil sites of which the 13 most important sites, especially those that yielded hominid remains, were inscribed in 1999 by UNESCO as the Cradle of Humankind World Heritage Site (COHWHS) (see Figure 1). More fossil sites yielding hominin fossils have been discovered since the declaration of this area as a World Heritage Site - the two most noteworthy ones are Malapa and the Rising Star (Dinaledi) Cave. This remarkable region yielded more hominin fossils than the rest of the world's palaeoanthropological sites put together. South Africa is the country with the longest record of hominin occupation in the world if one includes other sites such as Elandsfontein, Florisbad, Klasiesrivier, Blombos and Border Cave.

The Cradle of Humankind, in conjunction with Taung in Northwest and Makopane's Cave in Limpopo, yielded thousands of hominin fossils which range from single teeth to an almost complete skeleton in the case of Little Foot. The majority of these fossils belong to apemen such as Australopithecus africanus and Paranthropus robustus while very few COHWHS specimens could be attributed to the genus Homo before the discovery of the fossils in Dinaledi Chamber within the Rising Star Cave.

The fossils of A. africanus, which is the oldest member of the hominin family tree in South Africa, are dated at between 3 and 2 million years old (Herries \& Shaw 2011). A. africanus fossils have been discovered at Sterkfontein Caves (e.g. Mrs. Ples and Little Foot), Gladysvale, Taung and Makopane's Cave. Paranthropus robustus, which is dated between 2 million and 800000 years, has been found at Kromdraai, Swartkrans and Drimolen (Herries, Curnoe \& Adams 2009).

\section{The fossil sites of the Cradle of Humankind}

The term 'Cradle of Humankind' is misleading. Many hominin fossils that are evolutionarily closer to modern humans have been found elsewhere. So the name 'Site where a few branches and hopefully a piece of the trunk of the human family tree was discovered' might have been more correct, but it has not got the same ring to it. The reason for the abundance of Plio-Pleistocene fossils in the COHWHS has more to do with geology than the original distribution of hominins.

An extensive swathe of 2.2 billion year old dolomite extends over the northern part of South Africa. Over time it was covered over by younger formations including a kilometres thick layer of rocks constituting the Karoo Supergroup. As these were weathered away by erosion, the dolomite was exposed to weathering and dissolution in a process termed karstification, which includes the 


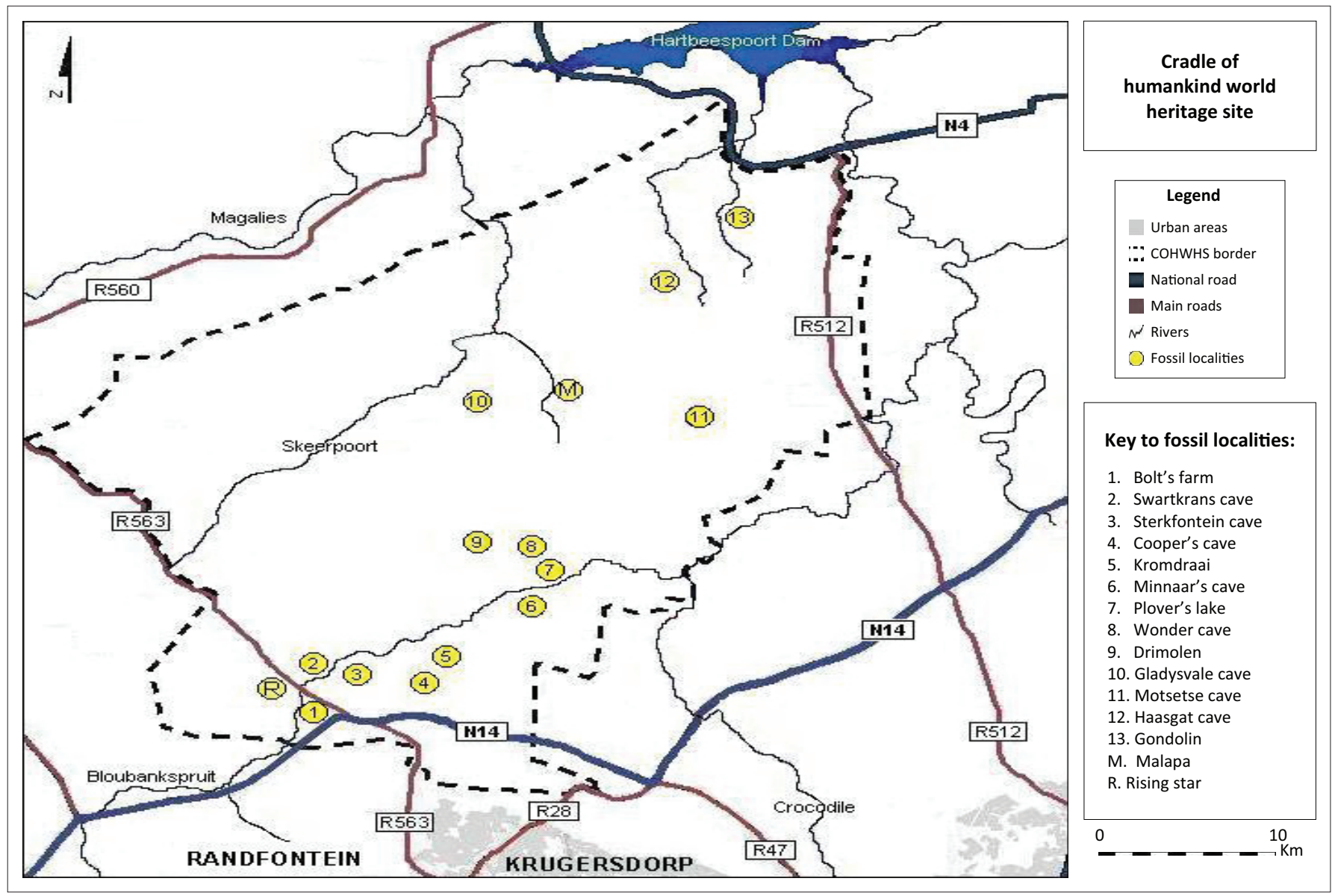

Source: Author's own work

FIGURE 1: The Cradle of Humankind World Heritage Site with the 13 fossil localities, which were inscribed by UNESCO.

formation of solution cavities, caves and sinkholes. From approximately 3 million years ago until the present, these caves and sinkholes provided shelter initially for bats and cavedwelling predators but later also tool and fire-wielding hominins. Hundreds of thousands of fossils have been excavated from these caves which are far more than the number of fossils that have been found in sandstone caves for instance. The alkaline environment created by the dissolution of the dolomite and calcite is responsible for the excellent preservation and mineralisation of fossil bones in these dolomite caves.

This geological fluke gave South Africa its remarkable fossil treasure. One of the common mistakes people makelayman and scientist alike - is that these fossils provide proof that the apemen, ${ }^{1}$ primitive humans ${ }^{2}$ or anatomically modern humans ${ }^{3}$ originated in South Africa. The more accurate view on this would be that although only about a quarter of the known homin 4 species (even if one accepts

1.In this article, pre-Homo hominins are referred to as apemen. This term is used in the same vein as the older term pithecanthrope (Greek for apeman). In time it was replaced by the term australopithecine, which unfortunately excludes other preHomo hominins including the genera Sahelanthropus, Ardipithicus and Paranthropus.

2.The term 'primitive humans' refers to members of the Homo genus, which do not belong to Homo sapiens.

3.Anatomically modern humans are members of Homo sapiens.

4.The term 'hominin' (subfamily Homininae) refers to all the species on the family tree between humans and the common ancestor, which humans share with chimpanzees. In the past, the term 'hominid' was used but more recently the chimpanzees and gorillas have been included together with the Homininae in the family Hominidae. the validity of Australopithecus sediba and Homo naledi) is represented in the COHWHS, it is the biggest and richest fossil repository of hominins in the world. Hominins were spread across Africa and would obviously have occurred in the region between the dolomite caves and the East African fossil sites. The only reasons why hominin fossils have not been found in Zimbabwe and Zambia is because of the geology of those countries or that palaeoanthropologists and the lay people in those countries have not established a good working relationship, because this is always so - lay people have discovered the majority of hominin species while the scientists get the fame and funding.

\section{Cave formation and the deposit of bones}

Claims that the roof of the Rising Star Cave is solid and there could not have been an alternative vertical ingress into the cave and that there is no evidence of deposition of bone by water are untrue (Dirks et al. 2015). All evidence points to the fact that the cave system, its formation, continuous dissolution and deposition of limestone and sediments are water-driven. The deposit of rocks, sediments and fossils has occurred and is still occurring by means of two factors - the ingress of water into the cave and gravity. 


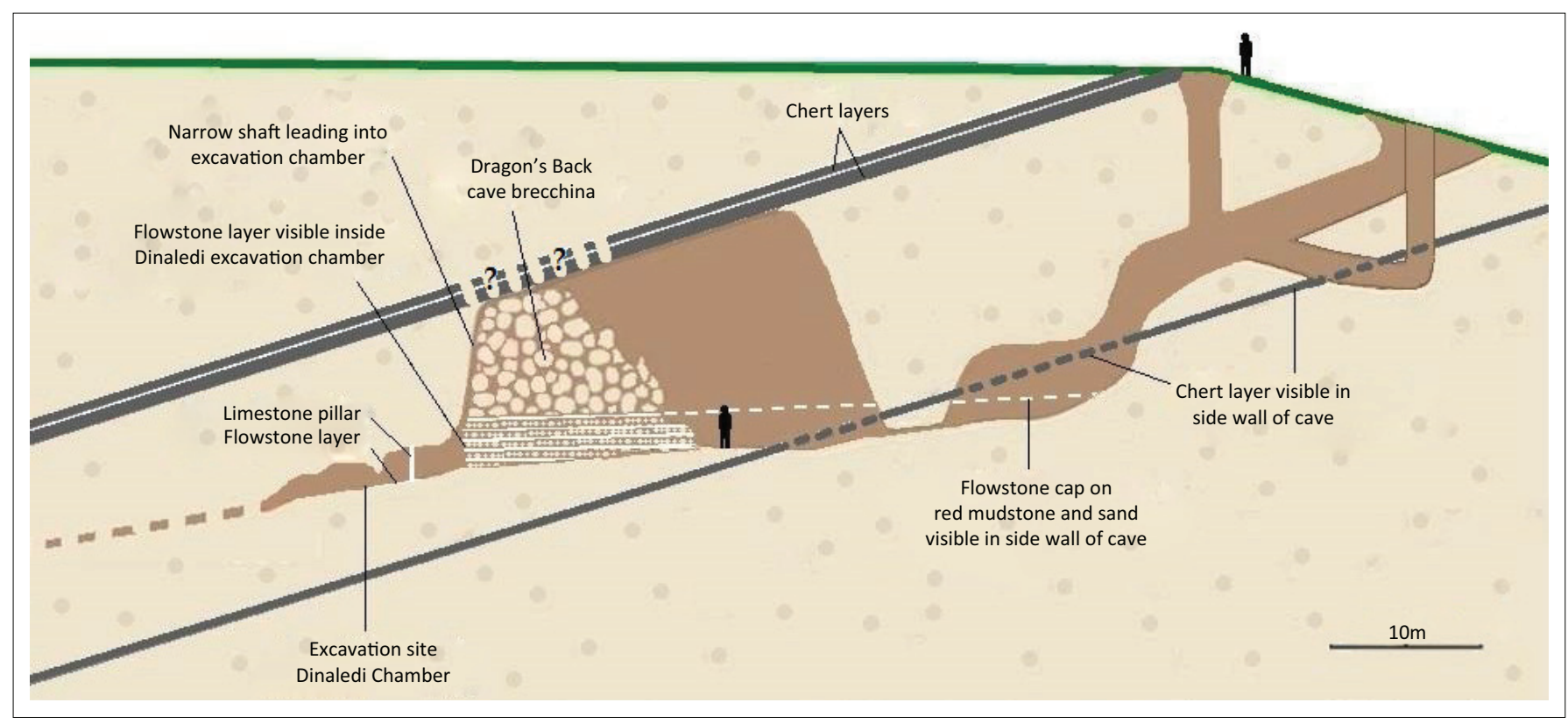

Source: Author's own work

FIGURE 2: Simplified profile through Rising Star Cave adapted from illustrations in Shreeve (2015) and Dirks et al. (2015).

The cave formed underground by means of the dissolution of rock and the widening of fissures in the dolomite. Water that penetrates the rock recharges the water table, which naturally drains through springs that feed rivers lower down in the epigean topography. The cave system becomes a conduit draining water from the surface above into the water table below and in the process continues to grow as the dolomite and limestone dissolve. Chert is more resistant to weathering and would often form a cave roof or overhang inside the cave. The Rising Star Cave clearly developed between such chert layers (see Figure 2).

The dolomite, limestone and chert layers were originally set down horizontally on the bottom of a 2.2 billion year old sea. The rock formations containing these layers were warped downward over time because of various geological processes. This slope of the rock layers and the relative impermeability of the chert layers determine the direction of flow of the water underground, which in turn determines the evolution of the solution cavities underground to a large degree.

The limestone component inside the dolomite dissolves over time and migrates with the water into the solution cavities when water slowly seeps through dolomite. The decalcified dolomite, called a wad, becomes very light and porous. Speleothems or limestone formations (stalactites, stalagmites, flowstone and dripstone formations) inside the cave form when the water table drops sufficiently and the solution cavity is filled with air and evaporation can take place.

The deposit of limestone inside the cave mirrors the topography of the cave and is obviously determined by the gravitational flow of water. The fact that limestone formations occur in the Rising Star Cave implies that dissolution of dolomite has or is still taking place above the point of its formation. In other words, water had to move from the surface down to the point of limestone formation. This fact disproves the statement that the cave roof is solid and there is no sign of an alternative vertical ingress into the cave (Dirks et al. 2015).

The dissolution of dolomite underground and the erosion of the external surface bring the surface and roof of the solution cavity closer to one another over time and eventually the roof becomes too thin and the wad too weak to support the weight of the overlying soil and eroded rock. The subterranean solution cavity is transformed into a cave when the roof collapses at such a weak point, forming a sinkhole and thereby an entrance into the solution cavity. The collapse of the roof sends boulders, sand and soil cascading down inside the solution cavity and a scree slope is formed if the shape of the solution cavity allows for this. The scree slope gives easy access to hominins and quadrupedal animals into the cave where they find shelter (see Figure 3).

Caves are neither stagnant nor permanent geological features and will continue to evolve by means of a process of continuous dissolution of dolomite and limestone resulting in continuous rock collapses, deposition of limestone and the ingress of water and organic material. Not all dolomite caves are fossiliferous. Fossils will only form if the physical and chemical conditions are just right. In some cases such as at Cooper's Cave, the prehistoric cave roof has eroded away leaving behind fossiliferous cave breccia on ground level. In other cases, new caves may form when erosion dissolves fossiliferous cave breccia, leaving fossils in the roof of the modern cave as one can see at Swartkrans Cave, Makopane's Cave and Gladysvale Cave (see Figure 4). 
Bones commonly enter the cave when predators such as hyenas and sabretooth cats drag their prey into the cave or may fall down into the cave from trees at the entrance of a cave where leopards may consume their prey (Brain 1993a). Hundreds of thousands of bones will accumulate inside the cave in this manner. Throughout this process, mud and sand will continue to wash into the cave to form the floor of the cave. In the meantime sporadic rock collapses continue inside the cave adding to the floor cover. Lime continues to drip down from the roof of the cave cementing all these components together. These are then the processes that contribute to the formation of fossiliferous cave breccia. At times there are more continuous amounts of water that drip through the roof of the cave resulting in layers of flowstone that cap the fossiliferous sediments on the cave floor. This clearly was the case in the Rising Star Cave (see Figure 2).

The fossils in the Dinaledi Chamber in Rising Star Cave occur on top and inside a layer of fine mud (Dirks et al. 2015;

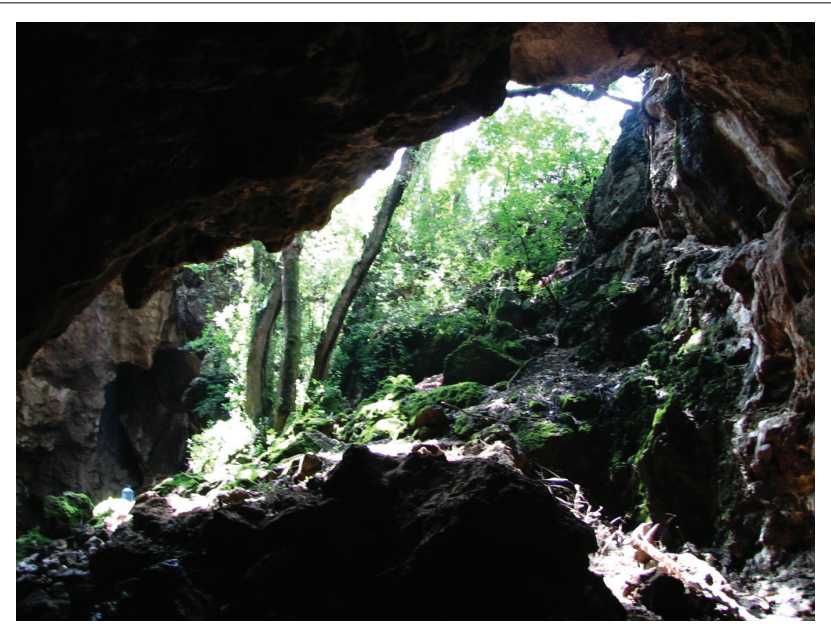

Source: Author's own work

FIGURE 3: A sinkhole on the farm Windgat in the Cradle of Humankind World Heritage Site.

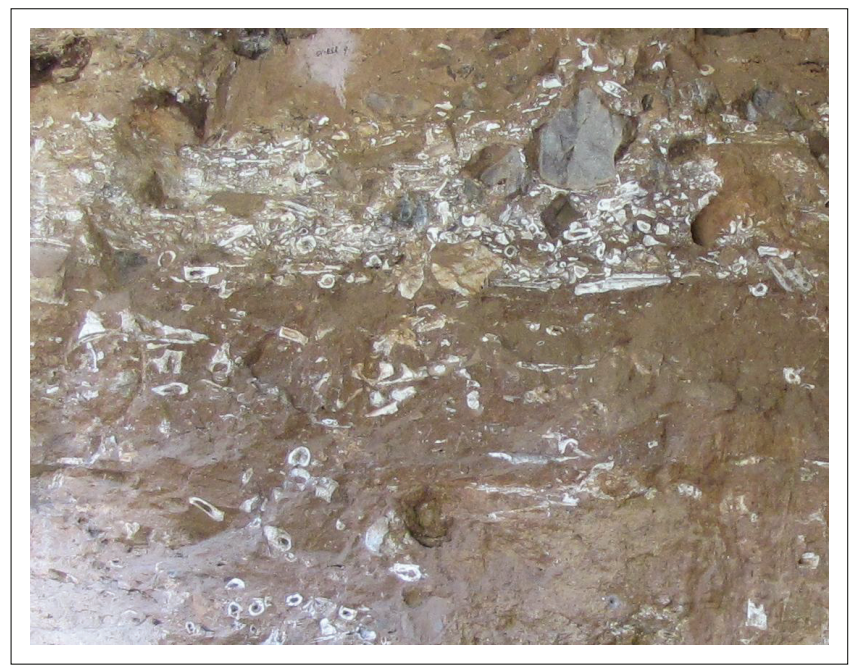

Source: Author's own work

FIGURE 4: Fossils in the roof of Gladysvale Cave.
Randolph-Quinney et al. 2016). This suggests that the fossils have weathered out from cave breccia higher up in the cave system and were transported and redeposited there together with the sediment by water. Makondos are common features in the COHWHS and at Makopane in Limpopo Province. Makondos form when the limestone binding the fossiliferous cave breccia dissolves (Brink \& Partridge 1980). The narrow shaft that passes behind the breccia pile called 'Dragons Back' into the fossiliferous Dinaledi Chamber, where the limestone layers and layers of cave breccia are exposed, could be such a makondo.

It is important to remember that caves in dolomitic areas are conduits that connect surface drainage to the subterranean aquifer and that their existence and evolution and the sedimentary processes inside the cave depend greatly on the flow of water.

It is highly probable that the narrow 12-m-high shaft was formed by running water over a period of time and that that water came through a hole in the roof which subsequently got filled up and is not visible any more. It is necessary to look at the Dragon's Back breccia more carefully. It is predicted that further investigation will show that Dragon's Back consists of fossiliferous cave breccia that has been deposited on top of older layers of flowstone alternating with layers of fossiliferous cave breccia that have been exposed by erosion in Dinaledi Chamber.

The fact that the fossil deposit contains the fossils of only one medium-sized vertebrate namely this particular hominin species was one of the reasons that inspired the assumption that Naledi buried its dead. If Rising Star had been an average fossiliferous cave, it is difficult to explain why the remains of only one species were discovered. Assemblages consisting of primarily mammal bones and a small percentage of hominin bones are the norm in the Plio-Pleistocene deposits in the COHWHS.

Death by disease and old age will occur mostly amongst old or very young individuals. The estimated ages of the hominin individuals at Rising Star range from three infants, three young juveniles, one older juvenile, one sub-adult, four young adults and one old adult (Dirks et al. 2015). This closely resembles a natural population consisting of individuals with a range of ages and this is exactly what one would expect when a family group experiences a catastrophic event where members have an equal chance of being killed, their remains deposited and fossilised (Bocquet-Appel \& Arsuaga 1999). Even though Dirks et al. (2015) mention this possibility, they still conclude that they prefer the burial or body disposal hypothesis.

It is obvious that the breccia constituting the Dragon's Back had to come from a position higher up. This is comparable to the talus cone found at the back of Wonder Cave (see Figure 5). 
The term 'talus cone' is used to describe a pile of rock, mud and sand that form underneath an opening in the roof of the cave when material washes or falls through the hole into the cave. This talus cone may also contain the remains of organisms. Over time, this talus cone may petrify and be indistinguishable from other forms of cave breccia. Little Foot was found in such a petrified talus cone. This ingress of material may happen over a long period of time or suddenly when the roof collapses to form a sinkhole. Under certain conditions, the hole in the roof may be blocked by falling boulders choking the opening. The opening disappears when sand, mud and smaller rocks fill in the cracks between the boulders over time and finally everything is cemented together when lime runs through this mix. This seems to have been the case in Wonder Cave where a blind aven is present above the talus cone, which does not open to the surface (see Figure 5). The mud, sand and animal bones in a talus cone evidently came from the surface and could not have been generated inside the cave, nor could it have entered elsewhere and be lifted up to a height of several meters. It is logical to assume that the same sequence of events formed Dragon's Back and that the chert layer forming the cave roof is not as intact as has been suggested (Dirks et al. 2015). The actual structure of the roof above Rising Star should be mapped with seismological equipment rather than drawing conclusions based on cavers' opinions.

There is mud on the fossil chamber floor and between the layers of flowstone exposed in the fossil chamber. This mud had to come from the surface as did the bones. The only question that remains is to determine the point of ingress. It is also important to keep in mind that the roof above the cave system has eroded away and has dropped several meters from where it was approximately 2 million years ago. This would mean that the present day entrance may not have existed when the fossils were deposited or if it did it would have been much narrower than today.

One could infer that some unusual action caused the hominin remains to be deposited there if the Dinaledi Chamber consisted only of pristine dolomite and limestone.

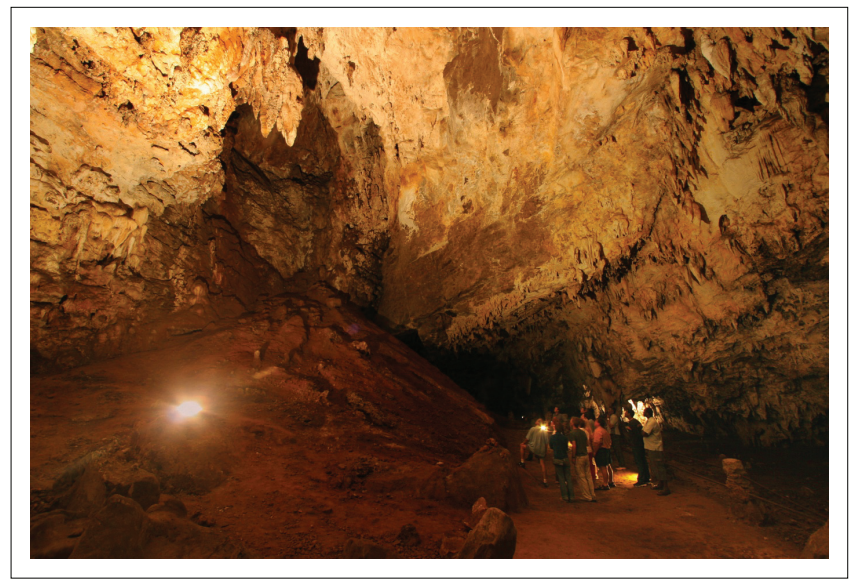

Source: (C) 2017 Tim Hauf Photography

FIGURE 5: Talus cone in Wonder Cave, Cradle of Humankind World Heritage Site.
The deposition of mud behind the 12-m-high Dragon's Back could mean only one of two things however - either the mud came through an opening that existed further uphill inside the cave before Dragon's Back was formed after which Dinaledi Chamber was sealed off from further deposition of mud from the rest of the cave system; or the mud could have eroded out from Dragon's Back itself, which would fit the talus cone hypothesis suggesting that this 12-m-high breccia pile contains mud, which only could come from outside. The conclusion of both scenarios is that water transported material from outside into the deepest reaches of the cave and that it would have played a role in the deposition of the bones as well.

The accumulation of bones of this single medium-sized vertebrate species associated with a talus cone could be explained by considering the possibility of a large Homo ergaster family group that used a choked sinkhole above the Rising Star Cave as a temporary shelter when the floor suddenly gave way and sent them tumbling down in the void below. This vertical opening into the void below would have prevented scavengers from being able to reach the bodies, which would explain the absence of mammal scavenger gnaw marks on the bones similar to the taphonomy at Malapa described by Val et al. (2015).

The absence of stone tools in the deposit was used as an argument for the burial hypothesis, but it seems as if the bones have eroded out and have been redeposited. Stones, being denser and heavier behave different from bones during the weathering, mobilisation and redeposition process. Again, the answer lies in the Dragon's Back breccia. It is probable that if there were any stone tools, they would be found amid the other rocks in the breccia.

The presence of bird and rodent bones in the fossil chamber could easily be explained if there had been a vertical opening above Dragon's Back, but it will defy explanation if the only entrance to the cave was $100 \mathrm{~m}$ away and on the other side of a 12-m-high barrier. Except for the odd visiting porcupine, rodents do not live in caves, especially not the dark zone. The hypothesis that rodent and bird bones could have entered the cave from an entrance near or further away from the current entrance and got washed down over a distance of over $100 \mathrm{~m}$ to be deposited at the far end of the cave before Dragon's Back was formed seems implausible.

Owls often roost at cave entrances in the twilight zone where they would regurgitate owl pellets containing the remains of their prey. Over time, a layer of micromammal bones will accumulate under the roost. Accumulations of micromammal bones are often used to determine the original prehistoric cave's entrance (Brain 1980). The simplest explanation for the distribution of rodent and even bird bones (especially if they turn out to be owl bones) is that it came from a position vertical to its place of deposition.

The majority of bones in the fossil chamber lies scattered around in no obvious association with each other (Val 2016). 
This does not support the assumption that these are the remains of bodies deposited into the cave. One would expect articulated bodies if this were the case. There are exceptions however - an articulated hand, ankle and lower leg of a child were discovered (Dirks et al. 2015). This could be an indication that body parts were subject to mummification and broke off and were redeposited further down in the cave system as units of bone bound in dried skin, which subsequently rotted away.

\section{The presence of Homo in the Cradle of Humankind World Heritage Site}

Before the discovery of the fossils at Rising Star Cave, the majority of hominin fossils in the Cradle of Humankind belonged to either Australopithecus or Paranthropus. In 1948 however, fossils of a different hominin was discovered at Swartkrans by Robert John Robinson (Broom \& Robinson 1949). These fossil teeth and jaws were smaller and more humanlike than those of the apemen thus far encountered. They called this hominin Telanthropus capensis.

After some debate about the identity of these fossils and the validity of $T$. capensis, Robinson conceded that the fossils belonged in fact to Homo erectus and the name Telanthropus was subsequently sunk (Robinson 1953). Later the African variety of $H$. erectus was renamed $H$. ergaster, although many researchers still refer to all the specimens from Eurasia and Africa of this clade as H. erectus (Berger et al. 2015).

Ron Clarke discovered a partial cranium (SK 847) amongst Paranthropus fossils in the collections at the Transvaal Museum and recognised it as being fossils of Homo rather (Clarke, Howell \& Brain 1970) (see Figure 6). These fossils have been the best evidence before the discovery of the Rising Star fossils for the existence of $H$. ergaster in South Africa.

One of the curious claims made by Berger et al. (2015) and Dirks et al. (2015) is that Naledi had a particularly small head. Two partial skulls were discovered amongst the 1550 bones from Dinaledi Chamber and the more complete one was used in a reconstruction using some of the postcranial bones in the collection (see Figure 9). However, the fossil bones belong to many individuals, and the majority was found disarticulated. It is impossible to be sure whether the skull and any of the postcranial bones in the collection actually belonged to the same individual.

It would be a fatal flaw if bones of different-sized individuals were used to do the reconstruction. This is particularly important if sexual dimorphism occurs in a species. In other words, if you put a skull of an adult female on the postcranial skeleton of an adult male in a sexual dimorphic species where the male is bigger than the female, one could expect the outcome to be like the reconstruction proposed by Berger et al. (2015). A relatively complete large tibia was used to calculate the length of the reconstructed individual

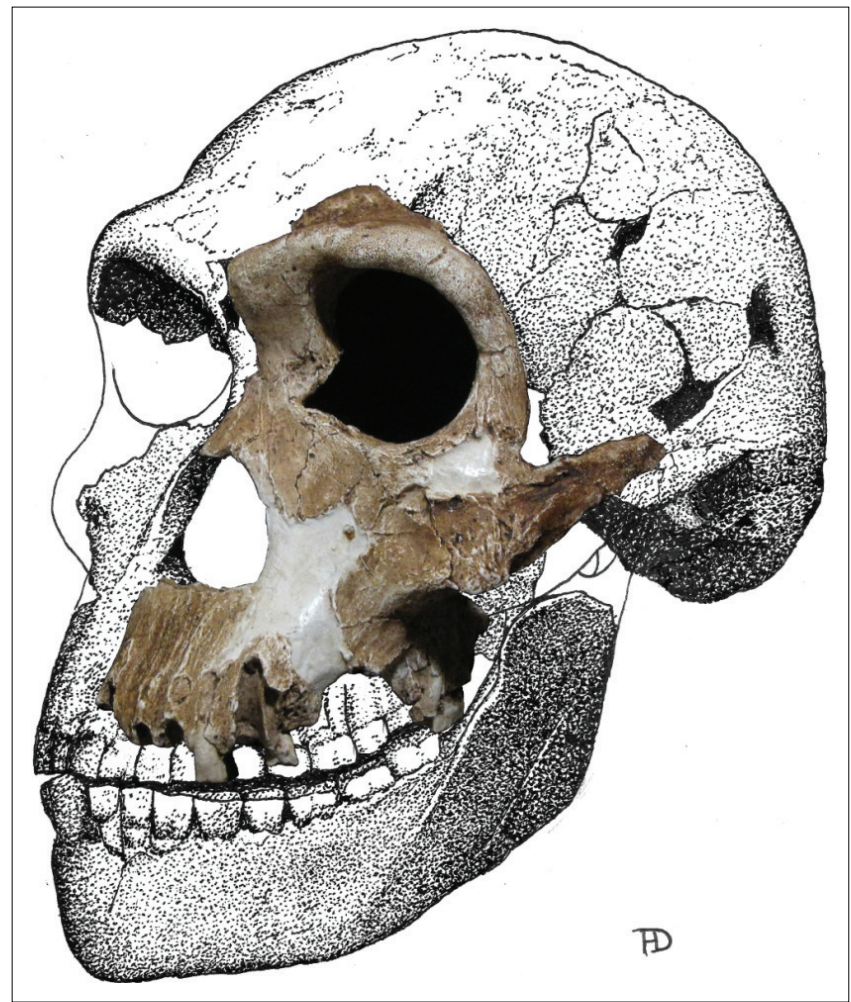

Source: Author's own work

FIGURE 6: Homo ergaster SK 847 (partial face and temporal bone) and SK 80 (maxilla) from Swartkrans superimposed on Neo (LES1) from Rising Star Cave.

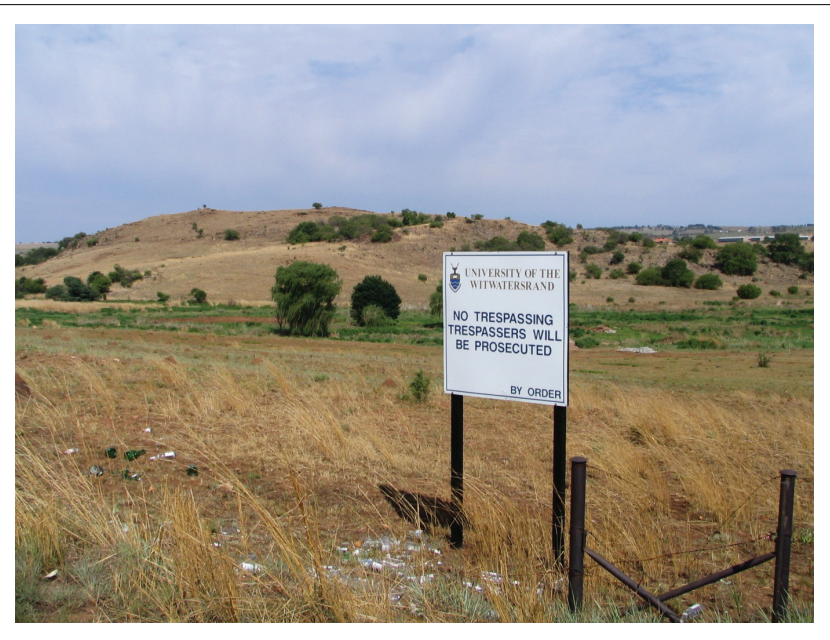

Source: Author's own work

FIGURE 7: Swartkrans palaeontological site is situated on the southern flank of the hill in the background.

as being between 144.5 and $147.8 \mathrm{~mm}$. The two braincases of Naledi available at the time (before the discovery of $\mathrm{Neo}$ ) were used to calculate a brain volume of approximately 560 cc and $465 \mathrm{cc}$ and the assumption was made that the larger one was that of a male and the smaller that of a female (Berger et al. 2015).

Hawks et al. (2017) reported new hominin specimens from the Lesedi Chamber, which forms part of the Rising Star Cave System. These fossils included a skull (LES1) with a brain capacity of 610 cc or $9 \%$ larger than that of the holotype (DH1) used in the original description (Berger et al. 2015). 
This skull dubbed Neo is now assumed to be a male specimen because it is larger than the holotype (LES1) (see Figure 9). This strongly suggests that the original assumption about Naledi having a remarkably small head for its body was wrong and that it was indeed a female skull reconstructed on a male body in a sexually dimorphic species.

The Naledi remains and the surrounding sediment in Lesedi Chamber have been dated at between 236000 and 335000 years by measuring the concentration of radioactive elements (Dirks et al. 2017). This date is as controversial as the claim that Naledi buried its dead and generates more questions than answers. It implies that Naledi either existed for more than one and a half million years without leaving any fossils or tools or that it originated relatively recently from yet another as yet undiscovered hominin species that has strong $H$. ergaster affinities.

\section{Discussion}

If Naledi is not $H$. ergaster, it is difficult to explain why we have never found $H$. naledi fossils anywhere else but in Rising Star Cave. It is difficult to ignore the fact that Rising Star Cave is virtually on the doorstep of Swartkrans where $H$. ergaster fossils were found (see Figure 8 ). The purported morphological differences between Naledi and $H$. ergaster seemed to centre originally on Naledi being small and $H$. ergaster being more robust and bigger (Berger et al. 2015). It is possible to find room for Naledi within the $H$. ergaster $/ H$. erectus clade if one takes sexual dimorphism and individual variation between individuals constituting this group as is demonstrated in the case of the Dmanisi skulls into consideration (Drobyshevskiy 2016; Durand 2015; Lordkipanidze et al. 2013; Stringer 2015; White 2015).

Thousands of early Oldowan-type tools associated with $H$. ergaster remains were excavated at Swartkrans and
Sterkfontein. If one assumes that Naledi is a different species from $H$. ergaster, it is difficult to explain why neither a separate stone industry nor any Naledi remains associated with any of the stone tools industries have been discovered. It is especially difficult to explain this hiatus in the fossil record and in the stone tool industries if one accepts the latest claim that Naledi is about 300000 years old and that they or their ancestors have existed for 1.5 million years without leaving a trace of their existence.

If Naledi was a contemporary of anatomically modern humans or their direct ancestors Homo heidelbergensis, then they would be irrelevant to the evolution of humans or their behaviour. If they coexisted with humans and were not much older than humans, they could not have given rise to humans and would become as irrelevant to human evolution as Homo floresiensis or P. robustus. The hypothesis that Naledi's buried their dead therefore cannot have any connection to Homo sapiens and Homo neanderthalensis burial practices and the whole concept of the oldest evidence for religious behaviour becomes a moot point.

The dating of the sediments and bone has been done with much care and the results should not be called into question.

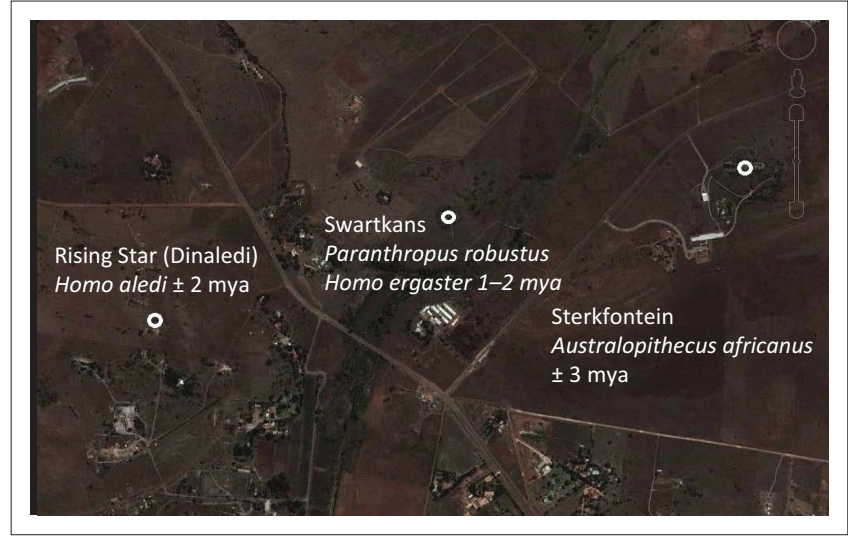

Source: Google Earth

FIGURE 8: The localities of Sterkfontein, Swartkrans and Rising Star and their relative position to one another.
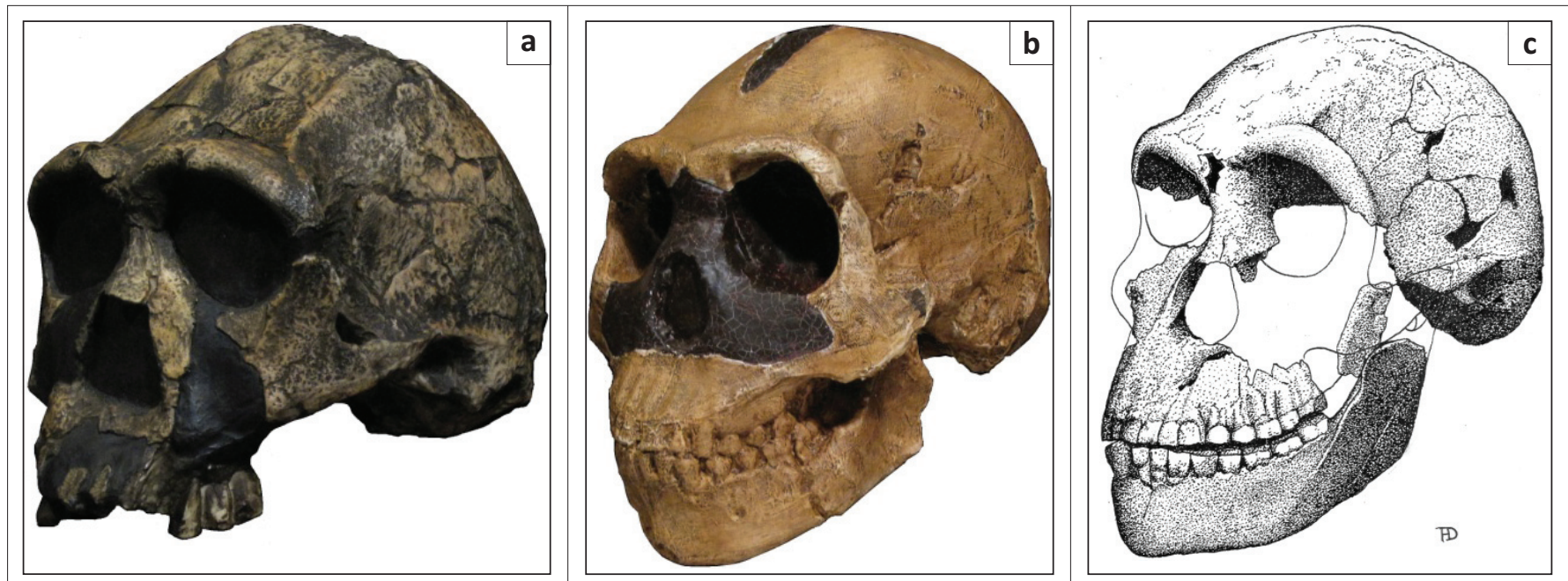

Source: Author's own work

FIGURE 9: A comparison of the skulls of Homo ergaster (a) (KNM ER 3733) from Koobi Fora, Kenya and the Naledi (b) (DH1) and Neo (c) (LES1) skulls from Rising Star Cave. 

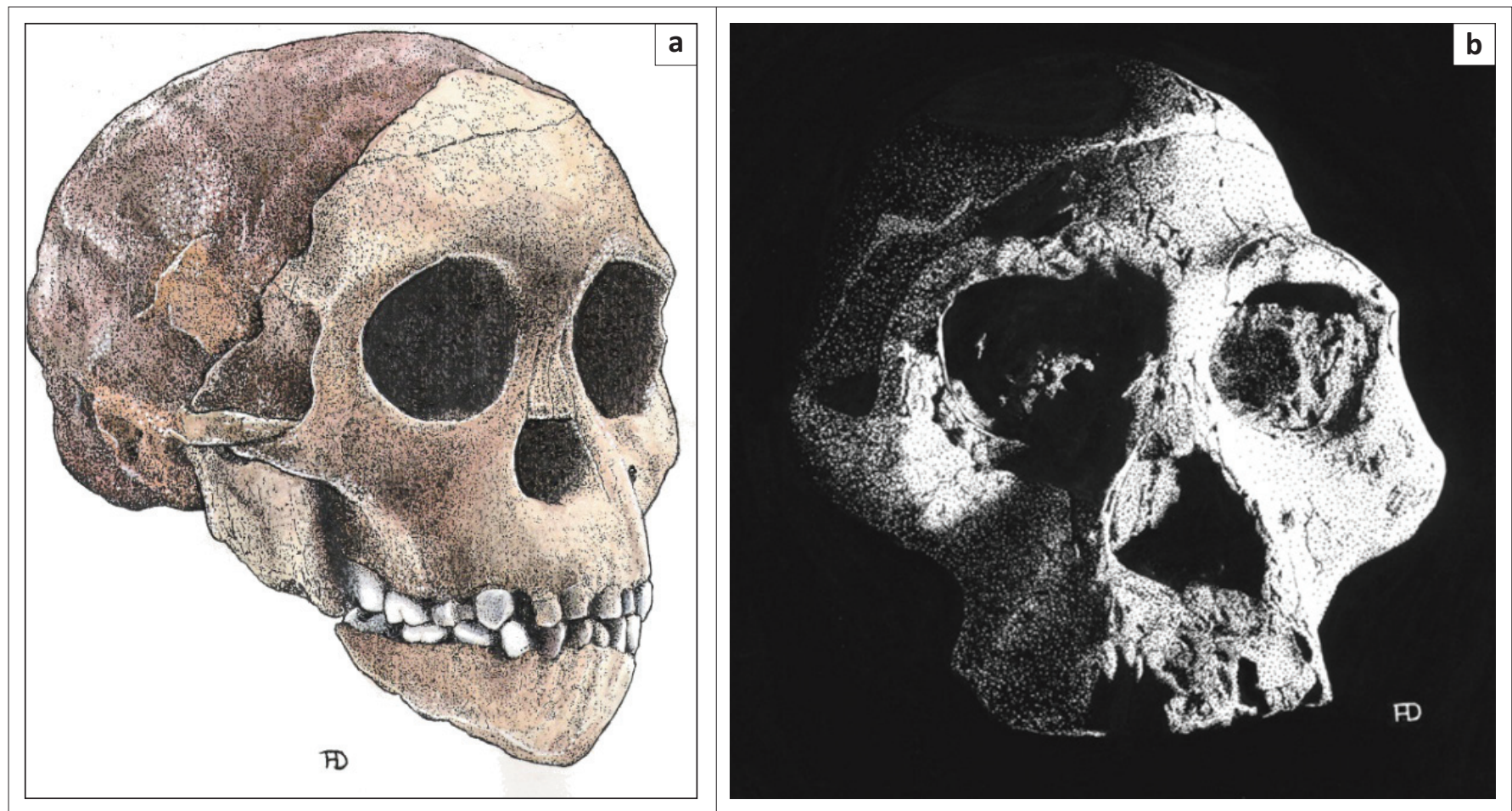

Source: Author's own work

FIGURE 10: (a) Australopithecus africanus juvenile (Taung Child); (b) A. africanus adult (Mrs. Ples).

What is debatable though is the interpretation of the data. The dating was done by means of measuring the uranium and thorium ratios in the teeth of the Naledi skulls and flowstone covering the remains. Unlike carbon, uranium does not occur naturally in animal or human bodies and is excreted as soon as possible. Uranium and its decay products leach out of the rocks of the Witwatersrand Supergroup, which lies adjacent to the COHWHS and can be found in the sediments, rivers and groundwater in the area (Durand 2012). Dirks et al. (2017) mentions that there have been cycles of reworking and more than one episode of the deposition of sediment in the Rising Star Cave. The groundwater that seeped through the dolomite, dissolved the lime and deposited the limestone evidently also carried uranium. If the uranium-containing water penetrated the fossils, it would explain how younger sediments and minerals could be found on and in much older fossils. Dirks et al. (2017) supplied us with a date of a later sedimentation event inside a cave system where the sediments underwent cycles of deposition, dissolution and redeposition and not the actual age of the fossils.

It is difficult to imagine how early Homo managed to navigate through a cave system with such tight squeezes while dragging bodies behind them (Val 2016). Even if they had fiery torches with them (of which there is no evidence), it would have been a very difficult feat to accomplish. The squeezes are very narrow - some only about $18 \mathrm{~cm}$ wide. The narrow shaft leading to Dinaledi Chamber is so narrow that one of the small, slim excavators (specially recruited for their skills and build) mentioned that she could control her decent by breathing. If these squeezes were fissures once that widened because of erosion and must surely have been smaller, if they were there at all during the time of Naledi. This alone would have made the cave inaccessible to any hominin at the time. There would have been many easily accessible caves and sinkholes in the region at the time where these primitive humans could have dumped the bodies without having to go through this trouble if they just wanted to get rid of the bodies. If Naledi is approximately 1.8 million years old, it is also difficult to explain why there is no evidence of human burial again until the discovery of a possible body disposal site at Atapuerca in Spain, which is attributed to Homo heidelebergensis and the H. neanderthalensis burials more than a million years later.

If a large family group was subject to a single cataclysmic event, it would produce the results seen in the Rising Star Cave including the range of ages the Naledi individuals represent and why fossils of other medium- to large-sized vertebrates are absent. It is more plausible to assume that the hominin remains found their way into the cave and were deposited in the same way as the rodent and owl bones through a vertical hole above the site of deposition. It is more parsimonious to accept that natural phenomena such as gravity and water were responsible for the deposition of these fossils rather than to attribute ritual behaviour to such primitive hominins.

Homin fossils have always been dragged into the Science/ Creation debate and the hominins of the Cradle of Humankind were probably more in the spotlight than hominins discovered elsewhere. For centuries, scientists tried to explain to their critics how natural phenomena were caused through natural processes instead of supernatural 
forces. The favouring of a romanticised interpretation of the deposition of the Naledi bones above a more pragmatic naturalistic explanation feeds the need of the masses for the supernatural and would explain its public appeal.

Hominin fossils could on the other hand also have a moderating effect on philosophical and religious views. Mrs. Ples (see Figure 10) was discovered on 18 April 1947 at Sterkfontein, about $2 \mathrm{~km}$ from the Rising Star Cave (see Figure 8). It was the first, almost complete, undistorted adult apeman skull ever discovered. When Raymond Dart described the first apeman fossil in 1925, the Taung Child skull (see Figure 10), he faced rejection from laypeople and scientists alike. The kindest of his critics said that the reason why the Taung Skull could not be accepted as the final evidence for the origin of humankind was because it was the skull of a child. Broom discovered fragmentary adult apeman remains from 1936 onwards, but with the discovery of Mrs. Ples, he had irrefutable proof of the existence of the so-called Missing Link. The Reformed Ecumenical Synod of 1949 accepted evolution as the most probable explanation for the origin and diversification of life on earth following this discovery (Durand 2009).

\section{Acknowledgements Competing interests}

The author declares that he has no financial or personal relationships which may have inappropriately influenced him in writing this article.

\section{References}

Berger, L.R., Hawks, J., De Ruiter, D.J., Churchill, S.E., Schmid, P., Delezene, L.K. et al., 2015, 'Homo naledi, a new species of the genus Homo from the Dinaledi Chamber, South Africa', eLife. 4. https://doi.org/10.7554/eLife.09560

Bocquet-Appel, J.P. \& Arsuaga, J.L., 1999, 'Age distributions of hominid samples at Atapuerca (SH) and Krapina could indicate accumulation by catastrophe', Journal of Archaeological Science 26, 327-338. https://doi.org/10.1006/jasc.1998.0370

Brain, C.K., 1980, 'Swartkrans as a case study in African cave taphonomy', Palaeontologia Africana 23, 73-74.

Brain, C.K., 1981, The hunters or the hunted? An introduction to African cave taphonomy, $376 \mathrm{p}$, The University of Chicago Press, Chicago, IL.

Brain, C.K., 1993a, 'A taphonomic overview of the Swartkrans fossil assemblages', in C.K. Brain (ed.), Swartkrans: A cave's chronicle of early man, Transvaal Museum Monograph 8, pp. 257-264, Transvaal Museum, Pretoria.

Brain, C.K., 1993b, 'Structure and stratigraphy of the Swartkrans cave in the light of new excavations', in C.K. Brain (ed.), Swartkrans: A cave's chronicle of early man, Transvaal Museum Monograph 8, pp. 23-33, Transvaal Museum, Pretoria.
Brink, A.B.A. \& Partridge, T.C., 1980, 'The nature and genesis of solution cavities (makondos) in Transvaal cave breccias', Palaeontologia Africana 23, 47-49.

Broom, R. \& Robinson, J.T., 1949, 'A new type of fossil man', Nature 164, 322-323. https://doi.org/10.1038/164322a0

Clarke, R.J., Howell, F.C. \& Brain, C.K., 1970, 'More evidence of an advanced hominid at Swartkrans', Nature 225, 1219-1222. https://doi.org/10.1038/2251219a0

Dirks, P.H.G.M., Berger, L.R., Hawks, J., Randolph-Quinney, P.S., Backwell, L.R. \& Roberts, E.M., 2016, Comment on 'Deliberate body disposal by hominins in the Dinaledi Chamber, Cradle of Humankind, South Africa?', Journal of Human Evolution 96, 149-153. https://doi.org/10.1016/j.jhevol.2016.04.007

Dirks, P.H.G.M., Berger, L.R., Roberts, E.M., Kramers, J.D., Hawks, J.L., RandolphQuinney, P.S. et al., 2015, 'Geological and taphonomic context for the new hominin species Homo naledi from the Dinaledi Chamber, South Africa', elife 4, e09561. https://doi.org/10.1038/2251219a0

Dirks, P.H.G.M., Roberts, E.M., Hilbert-Wolf, H., Kramers, J.D., Hawks, J., Dosseto, A. et al., 2017, 'The age of Homo naledi and associated sediments in the Rising Star Cave, South Africa', eLife 6, e24231. https://doi.org/10.7554/eLife.24231

Drobyshevskiy, S.V., 2016, 'Вспоминая телантропов: крах “теории Homo naledi”?', Антропогенез.PУ, viewed 15 January 2016, from http://antropogenez.ru/singlenews/article/578

Durand, J.F., 2009, 'The courage to face empirical reality: A biological perspective', in C.W. du Toit (ed.), The evolutionary roots of religion - Cultivate, mutate or eliminate? South African Science and Religion Forum (SASRF) Series 13, pp. 53-81, Research Institute for Theology and Religion, University of South Africa, Pretoria.

Durand, J.F., 2012, 'The impact of gold mining on the Witwatersrand on the rivers and karst system of Gauteng and North West Province, South Africa', Journal of African Earth Sciences 68, 24-43. https://doi.org/10.1016/j.jafrearsci.2012.03.013

Durand, J.F., 2015, 'Ander teorie oor Homo naledi: Meegesleur in modderstorting. Interview with Beeld', Netwerk 24, viewed 15 January 2016, http://www.netwerk24. com/Stemme/Aktueel/Homo-Naledi-Meegesleur-in-modderstorting-20150915

Hawks, J., Elliott, M., Schmid, P., Churchill, S.E., De Ruiter, D.J., Roberts, E.M. et al., 2017, 'New fossil remains of Homo naledi from the Lesedi Chamber, South Africa', eLife 6, e24232. https://doi.org/10.7554/eLife.24232

Herries, A.I.R., Curnoe, D. \& Adams, J.W., 2009, 'A multi-disciplinary seriation of early Homo and Paranthropus bearing palaeocaves in southern Africa', Quaternary International 202, 14-28. https://doi.org/10.1016/j.quaint.2008.05.017

Herries, A.I.R. \& Shaw, J., 2011, 'Palaeomagnetic analysis of the Sterkfontein palaeocave deposits; age implications for the hominin fossils and stone tool industries', Journal of Human Evolution 60, 523-539. https://doi.org/10.1016/j. jhevol.2010.09.001

Lordkipanidze, D., Ponce de León, M.S., Margvelashvili, A., Rak, Y., Rightmire, G.P., Vekua, A. et al., 2013, 'A complete skull from Dmanisi, Georgia, and the evolutionary biology of early Homo', Science 342(6156), 326-331. https://doi. org/10.1126/science.1238484

Randolph-Quinney, P.S., Backwell, L.R., Berger, L.R., Hawks, J., Dirks, P.H.G.M., Roberts, E.M. et al., 2016, 'Response to Thackeray (2016) - The possibility of lichen growth on bones of Homo naledi: Were they exposed to light?', South African Journal of Science 112(9/10), Art. \#a0177, 1-5. https://doi.org/10.17159/sajs.2016/a0177

Robinson, J.T., 1953, 'The nature of Telanthropus capensis', Nature 171, 33. https:// doi.org/10.1038/171033a0

Shreeve, J., 2015, 'Mystery man', National Geographic 228(4), 30-57.

Stringer, C., 2015, 'Human evolution: The many mysteries of Homo naledi', elife 4, e10627. https://doi.org/10.7554/eLife.10627

Val, A., 2016, 'Deliberate body disposal by hominins in the Dinaledi Chamber, Cradle of Humankind, South Africa?', Journal of Human Evolution 96, 145-148. https:// doi.org/10.1016/j.jhevol.2016.02.004

Val, A., Dirks, P.H.G.M., Backwell, L.R., D'Errico, F. \& Berger, L.R., 2015, 'Taphonomic analysis of the faunal assemblage associated with the hominins (Australopithecus sediba) from the Early Pleistocene cave deposits of Malapa, South Africa', PLoS One 10(6), e0126904. https://doi.org/10.1371/journal.pone.0126904

White, T., 2015, 'as reported by Ray Hartley, Some bones to pick', The Times, viewed 18 Sept, from http://www.timeslive.co.za/thetimes/2015/09/18/Some-bones-to-pick1 